\title{
REFUSAL OF TREATMENT BY MENTALLY COMPETENT PATIENT: THE CHOICE OF DOCTOR-PATIENT RELATIONSHIP MODELS
}

\begin{abstract}
Andrei M. Beliaev
General Surgery Deparment, Middlemore Hospital, Auckland, New Zealand

Summary: Introduction: In modern medicine professional relationship between the clinician and the patient is patient-centered. Patients become actively involved in the treatment decision making process and are encouraged to express their health-related preferences. Some patients may, however, refuse a favorable risk/benefit ratio treatment. This manuscript presents three cases of refusal of treatment by mentally competent surgical patients and discusses differences in their management. Conclusion: To achieve the best medical outcome for patients who possess the Actual Understanding test of mental competence clinicians use the deliberate model of medical professional relationship. For patients demonstrating the Understanding test of mental competence and wishing to utilize their health-related preferences physicians are obliged to deploy the interpretive model of doctor-patient relationship. In mentally competent patients with an illness-induced acute psychological regression the interpretive model of doctor-patient relationship as an initial strategy and cognitive behavior therapy can be useful in modifying treatment rejecting behavior and improving medical outcome.
\end{abstract}

Key words: Doctor-patient relationship; Mental competence; Health-related preferences; Illness-induced psychological regression

\section{Introduction}

In modern medicine relationship between the health care provider and the patient has become client-centered. Patients assume the role of an equal partner and being fully informed about risks and benefits of a diagnostic procedure or treatment are empowered to exercise their rights of autonomous decision-making. Unfortunately, some mentally competent patients can refuse a favorable risk/benefit ratio treatment, which endangers their own health and even lives. For example, refusal of blood transfusion after surgery has the odds of death of 2.5 for every ten units of hemoglobin drop below $80 \mathrm{~g} / \mathrm{L}$. This manuscript presents three cases of treatment refusal by mentally competent patients and discusses the use of different doctor-patient relationship models based on patient's decision making capacity, their health-related preferences and an illness-induced psychological regression.

Case 1. Ms. B was a young German traveler who was admitted with a three days history of right iliac fossa pain, nausea, vomiting and fever. At surgery her perforated gangrenous appendix was removed and she was started on intravenous antibiotics. Despite of continuing spikes of fever, Ms. B refused medications and insisted on being discharged from hospital. During interview she revealed that she would like to continue treatment, but felt financially insecure if she had to pay for her treatment. The patient was reassured that her travel insurance would cover her treat- ment costs. Additionally, nursing staff helped the patient to contact the travel insurance company to solve the issue. As a result, Ms. B. agreed to stay in hospital for a few more days, completed a course of intravenous antibiotics and was discharged from hospital in a good health.

Case 2. Mr. S, 56 years of age gentlemen, was admitted for an elective aortic valve replacement for severe aortic stenosis and coronary artery grafting. Patient's past medical history included non-Hodgkin's lymphoma which was treated with chemo-and radiotherapy to the chest 40 years ago. At surgery an extensive calcification of the entire ascending aorta was discovered which precluded an intended operation and would require a replacement of the entire aortic root. Furthermore, mediastinal lymph nodes were found to be enlarged which, in turn, raised the possibility of reactivation of patient's lymphoma. Because of a new surgical procedure has a higher mortality and morbidity rate than an aortic valve replacement mentioned in the informed consent, the decision was made not to proceed with surgery before discussing the matter with the patient. The lymph nodes biopsy was taken and the thoracotomy wound was closed. Biopsy results were consistent with diffuse large Bcell lymphoma. Clinicians explained to the patient and his family members that an undergoing a proposed operation followed by an aggressive chemotherapy would increase chances of curing his lymphoma. However, the patient declined a proposed surgery and elected to undergo a course of a less aggressive chemotherapy for his lymphoma. 
Case 3. Mr.Y presented for an elective coronary artery bypass surgery. Patient's psychiatric co-morbidity included schizo-affective disorder, bipolar type for which he was previously on a thymoleptic medication. Postoperatively, soon after transfer from an intensive care unit to the ward it was noticed that the patient became irritable, impulsive and verbally abusive to the medical staff. He also refused to take medications and threw out his food and medications on the floor. An on call clinician was informed about the patient's treatment refusal and aggressive behavior. During an interview, Mr.Y denied having any hallucinations and delusions. Mr. Y revealed that he was very upset and angry because the patient's son did not want to visit him in hospital after his surgery. Patient's affect appeared to be appropriate, of slightly hightened intensity, mobile, reactive and in the full range. His speech was coherent. There were no disorganized behavior. Mr.Y also had profound fears of abandonment and started to complain about a "bad medical care”. Patient's experiences, health-care expectations and preferences had been elicited by the doctor. Also the clinician emotionally and cognitively validated the patient, then he discussed with the patient possible reasons for his son's nonattendance such as medical staff did not contacted the son after patient's admission from intensive care unit to the ward, son might be afraid of visiting the ICU, he might be very busy at work and already obtain information about the patient from his mother and so on (Cognitive continuum technique). Then the clinician asked the patient about some very good things his son did for him for the last two weeks, last month and last year. This resulted in patient's conclusion that his son loved him and would want to see him in hospital (Acting "As If" cognitive modification technique). In addition, the clinician asked the patient to play the role of a doctor who must convince his patient (the role of a doctor) to continue treatment with medications after a major cardiac surgery ("Devil's advocate" technique). Furthermore, the physician and the patient elaborated on treatment goals and established that achieving the best medical outcome would be the most desirable patient's preference. Finally, the patient and the doctor reached a therapeutic contract. Accordingly, Mr.Y agreed to resume his medications in an exchange for the doctor's promise to contact patient's son next morning, and ask him to visit the patient. Thereafter, the patient was medication compliant and was able to engage in and maintain a good therapeutic relationship with other health care providers.

\section{Discussion}

It is widely known that a good doctor-patient relationship can improve patients' adherence to treatment. Professional relationship between health care providers and patients, including those who refuse treatment, is largely based on an assessment of patients' decision making capacity and their health-related preferences. If the patient's treatment goal is to achieve the best medical outcome, then clinicians deploy the deliberate model of doctor-patient relationship. This model is based on the Actual Understanding Test of mental competence of the patient. In case 1 patient's lack of knowledge about travel insurance and her feelings of financial insecurity were the reasons for refusal of treatment and requests for a hospital discharge. Re-emphasizing treatment goals, providing information and practical help usually resolve an issue of refusal of treatment.

In addition, to prevent treatment refusal and persuade the patient to accept doctor's treatment suggestions it is of paramount importance that the clinician not only demonstrates an affiliative affective behavior, but also is able to establish a mutually trustful therapeutic relationship. Patient's trust in a physician as a person will lay ground for the establishment of patient's trust in clinician's professional skills which the client is unable to judge due to a lack of medical knowledge. Clinician's affiliative communication style such as being warm, friendly, showing interest and desire to help, genuineness, devotion, honesty, non-judgmental attitude reduces patient's fears about illness, facilitates disclosure of personal information, and increases client's treatment adherence.

Cultural safety is an another essential element of an effective doctor-patient relationship. For example, in New Zealand, extended family members of a Maori or Pacific Island patient are involved in a shared decision-making and discussions of treatment progress from early stages of doctor-patient communication. This usually takes precedence in the form of scheduled family meetings. It is also extremely helpful that a social worker, occupational therapist and physiotherapist from the same ethnic background to be involved in such gatherings.

Furthermore, clinicians should use language which can be easy to understand by the layperson and reduces the patient's sense of vulnerability. For instance, while providing treatment in a hospital ward the clinician should explain to the patient the concept of multidisciplinary approach and use the word "We" instead of "I" at critical moments to demonstrate to the patient and his/her family members clinician's close collaboration with other colleagues. In a teaching hospital, it is a good medical practice to arrange a consultation with an academic medical professional.

Encouragement is another useful strategy. The doctor should provide an anxious patient with medical information through the use of words such as "Survival" and not "Mortality". It is unnecessary to exaggerate negative outcomes of treatment. Clinicians should always instill hope in their patients. In some cases it is necessary to appeal to patient's sense of responsibility to him/herself and his/her family.

In some cases utilization of patient's health-related preferences is the goal of treatment. As long as such patients can weigh and choose among different treatment options (positive test of Understanding of mental competence) clinicians are obliged to use the interpretive model of doctor-patient relationship, which is centered on patient's health-related values, even if the patient's decision will work against his/her 
own best. In New Zealand an institution of medical treatment to the mentally competent patient who objects it is considered as the criminal offence of assault.

In this model, patient's values, beliefs, assumptions and schemas are not challenged by the doctor. On the other hand, they are respected and validated. After clarification of patient's values the clinician thoroughly explains to the patient the whole array of diagnostic and treatment options available to the client.

Additionally, the doctor must fully disclose to the patient risks and benefits of these options and their alternatives. The physician must be sure that the patient sufficiently comprehends the matter and its consequences. It is entirely up to the fully informed patient to choose the most suitable option to utilize his/her subjective health-related values.

Mr. S. (case 2) valued his current condition more favorably than doctor's suggestion to have a more serious cardiac operation followed by a chemotherapy with a better prospect of cure of his lymphoma. Therefore, he declined that doctor's suggestion. Another example of the use of the interpretive model of doctor-patient relationship would be to operate on a Jehovah's Witness patient who objects blood transfusion on religious grounds.

The third situation arises when patient's dysfunctional cognition and maladaptive treatment rejecting behavior hinders an achievement of any treatment goal. Here, an application of the deliberate or interpretive model of doctorpatient relationship would be counterproductive, because it does not acknowledge an illness-induced acute psychological regression of the patient and, therefore, does not address his/her cognitive needs.

The concept of an illness-induced psychological regression originates from the Freudian theory of personality. Personality can be defined as enduring patterns of behavior that reflect an individual's values and belief system, personal goals, standards, and understanding of the external world. According to Freud, personality consists of a tripartite psychic structure: the Id, Ego, and Superego. The Id is a collection of primitive instincts and drives. The Ego is a regulatory formation designed to settle conflicts between the Id, Superego, and external reality. The Ego functions are as follows: control and regulation of instinctual drives, affects and impulses, reality testing, judgment, object relations, sense of reality of the world and the self, thought process, autonomous functioning, synthetic-integrative function, stimulus barrier, defensive operations, adaptive regression in the service of the Ego, and mastery-competency function. The last component of personality is the Superego, which represents an internalization of social norms and values. According to the Freudian theory, from time to time, anxiety and depression can arise from conflicts between these elements of personality and in order to suppress subconscious discomfort caused by these conflicts, and maintain a sense of self-esteem and self-worth, the Ego employs its defense mechanisms.

Defense mechanisms or operations are intra-psychic processes and behaviors that reconcile internal drives with ex- ternal demands. They have been conceptually arranged in the following maturational hierarchy: psychotic defenses, immature or borderline, neurotic, and mature or normal defenses. Psychotic defenses comprise psychotic denial, psychotic distortion, and delusional distortion. Immature defenses consist of passive aggression, acting out, dissociation, projection, autistic fantasy, devaluation, idealization, and splitting. Intellectualization, isolation, repression, reaction formation, displacement, somatization, undoing and rationalization belong to the level of neurotic defenses. The mature defenses include suppression, altruism, humor, and sublimation.

It has been hypothesized that certain personality disorders stem from maturational arrest in Ego development. Even more important for clinical practice is the fact that under the stress of general medical illness patients may psychologically regress, i.e. regress down the maturational hierarchy of defense mechanisms and even acquire borderline personality traits. For instance, in burn survivors psychological impairment and psychiatric disorders were found in $45.5 \%$ and $46.6 \%$ of patients, respectively. Case 3 is an example of the borderline spectrum an acute psychological regression in a patient who underwent a major cardiac surgery.

In their behavior, borderline individuals often sway between narcissistic tendencies and expect to be treated as important persons, and masochistic trends, i.e., viewing themselves as profoundly inadequate and worthless. Also they may have paranoid traits as well and be convinced that other people want to harm them. They may also perceive clinician's treatment suggestions as a threat to their sense of self, recruit image-distorting defense mechanisms and refuse treatment. Furthermore, often these patients have a lack of trust in authority figures, and are prone to distort environmental clues. Therefore, to avoid these scenario clinicians should recognize characteristic disruptive behavior and select the interpretive model of doctor-patient relationship as an initial strategy. Cognitive behavior therapy (CBT) plays an important role in modifying borderline patients' dysfunctional cognition and behavior. Case 3 shows that CBT can be a very effective psychotherapeutic intervention for modification of the patient's medication refusal. It, probably, results from a short-lived transitory nature of patient's psychological regression.

Interestingly, Kernberg (1996) proposed a psycho-dynamic theory of personality organization. On the basis of patients' Ego functions such as reality testing, identity diffusion status, and a predominant level of defensive operations individuals habitually use he divided patients into psychotic, borderline, and neurotic personality organization categories. According to the Kernberg's theory, patients with borderline personality organization are characterized by an intact reality testing, marked identity diffusion and primitive psychological defenses (projection, denial, distortion, splitting). In the abovementioned case 3 , however, the patient used image-distorting defenses, but there were no signs of identity diffusion. This case illustrates that the Kernberg's theory of personality organization does not fully ex- 
plain psycho-dynamic changes in patients with an acute psychological regression.

Another contextual validity disagreement arises from consideration of the Kernberg's reality testing scale of personality organization, which, unfortunately, does not allow clinicians to determine patient's decision making capacity (making a choice, understanding, appreciation and reasoning) and provide with a realistic foundation on which an effective doctor-patient relationship should rest. On the other hand, mental competence which includes insight and judgment is broader than the Kernberg's reality testing concept and has important medico-legal implications for doctor-patient relationship.

In conclusion it can be said that clinicians taking care of patients who refuse treatment have to consider not only patients' mental competence and treatment preferences, but also to account for patients' illness-induced psychological regression. To achieve the best medical outcome for patients who possess the Actual Understanding test of mental competence clinicians should use the deliberate model of medical professional relationship. For patients demonstrating the Understanding test of mental competence and wishing to utilize their health-related values physicians are obliged to deploy the interpretive model of doctor-patient relationship. In mentally competent patients with an illness-induced acute psychological regression the interpretive model of doctor-patient relationship as an initial strategy and CBT can be useful in modifying treatment rejecting behavior.

\section{References}

1. Bandura A. Social Cognitive Theory of Personality. In: Pervin LA, John OP, editors. Handbook of Personality. Second ed. New York: The Guilford Press; 1999. p. $154-96$.

2. Beauchamp TL, Childress JF. Principles of biomedical ethics. Fifth ed. New York: Oxford University Press; 2001.

3. Beck J.S. Cognitive Therapy: Basics and Beyound. New York: The Guilford Press; 1995.

4. Bertakis K.D., Roter D., Putnam S.M. The relationship of physician medical interview style to patient satisfaction. J Fam Pract. 1991;32(2):175-81.

5. Beutler LE, Groth-Marnat G, Rosner R. Introduction to Integrative Assessment of Adult Personality. In: Beutler LE, Groth-Marnat G, editors. Intergrative Assessment of Adult Personality. Second ed. New York: The Guilford Press; 2003.

6. Blacher RS. The psychological and psychiatric consequences of the ICU stay. European Journal of Anaesthesiology - Supplement. 1997 May; 15: 45-7.

7. Bond M, Gardner ST, Christian J, Sigal JJ. Empirical study of self-rated defense styles. Archives of General Psychiatry. 1983 Mar; 40(3): 333-8.

8. Cape J. Patient-rated therapeutic relationship and outcome in general practitioner treatment of psychological problems. British Journal of Clinical Psychology. 2000 Nov; 39(Pt 4): 383-95.

9. Carson JL, Noveck H, Berlin JA, Gould SA. Mortality and morbidity in patients with very low postoperative $\mathrm{Hb}$ levels who decline blood transfusion. Transfusion. 2002 Jul; 42(7): 812-8.
10. Coates J. Refusing emergency life-sustaining treatment. NZ Med J. 2001;114:18.

11. Emanuel EJ, Emanuel LL. Four models of the physician-patient relationship. In Steinbock B, Arras JD, London AJ, editors. Ethical Issues in Modern Medicine. Sixth ed. Boston MA: McGraw-Hill; 2003. p. 67-76.

12. Groth-Marnat G. Handbook of Psychological Assessment. Fourth ed. Hoboken, New Jersey: John Wiley \& Sons, Inc; 2003.

13. Huffman JC, Stern TA, Harley RM, Lundy NA. The use of DBT skills in the treatment of difficult patients in the General Hospital. Psychosomatics. 2003 SepOct; 44(5): 421-9.

14. Johnstone M-J, Kanitsaki O. Health Care Provider and Consumer Understandings of Cultural Safety and Cultural Competency in Health Care: An Australian Study. Journal of Cultural Diversity. 2007 Summer; 14(2): 96-105.

15. Kaplan HI, Sadock BJ, Grebb JA. Kaplan and Sadock's Synopsis of Psychiatry: Behavioral Sciences. Clinical Psychiatry. Seventh ed. Baltimore: Williams \& Wilkins; 1994

16. Kernberg OF. A Psychoanalytic Theory of Personality Disorders. In: Clarkin JF Lenzenweger MF, editors. Major theories of personality disorders. New York: The Guilford Press; 1996. p. 106-40.

17. Kernberg PF. Mechanisms of defense: development and research perspectives. Bulletin of the Menninger Clinic. 1994 Winter; 58(1): 55-87.

18. Keszthelyi S, Blasszauer B. Challenging non-compliance. J Med Ethics. 2003; 29: 257-9.

19. Lenzenweger MF, Clarkin JF, Kernberg OF, Foelsch PA. The Inventory of Personality Organization: psychometric properties, factorial composition, and criterion relations with affect, aggressive dyscontrol, psychosis proneness, and self-domains in a nonclinical sample. Psychological Assessment. 2001 Dec; 13(4): 577-91.

20. Linehan M. M. Cognitive-Behavioral Treatment of Borderline Personality Disorder. New York: Guilford Press; 1993.

21. Little P, Everitt H, Williamson I. Observational study of effect of patient centredness and positive approach on outcomes of general practice consultations. BMJ. 2001 Oct 20; 323(7318): 908-11.

22. Madianos M.G, Papaghelis M, Ioannovich J, Dafni R. Psychiatric disorders in burn patients: a follow-up study. Psychotherapy \& Psychosomatics. 2001; 70(1): $30-7$.

23. Meissner W.W. Treatment of Patients in the Borderline Spectrum: An Overview. American Journal of Psychotherapy. 1993; 47(2): 184-93.

24. Mold J.W. Facilitating Shared Decision Making with Patients. American Family Physician. October 1, 2006; 74(7).

25. Richardson S., Williams T. Why is cultural safety essential in health care? Medicine and Law. 2007 Dec.; 26(4): 699-707.

26. Roth LH, Meisel A, Lidz CW. Tests of Competency to Consent to Treatment. Am J Psychiatry. 1977 Mar; 134(3): 279-84

27. Selzer MA, Koenigsberg HW, Kernberg OF. The initial contract in the treatment of borderline patients. Am J Psychiatry. 1987; 144(7): 927-30

28. Shea S.C. Psychiatric Interviewing: the art of understanding. A Practical Guide for Psychiatrists, Psychologists, Counselors, Social Workers, Nurses, and Other Mental Health Professionals. Second ed. Philadelphia: W.B. Sounders Company; 1998.

29. Simon J.R. Refusal of Care: The Physician-Patient Relationship and Decisionmaking Capacity. Ann Emerg Med. 2007; 50: 456-61.

30. Stewart M.A. What is a Successful Doctor-Patient Interview? A Study of Interactions and Outcomes. Soc Sci Med. 1884; 19(2): 167-75.

31. Stuhlmiller DFE, Cudnik MT, Sundheim SM, Threlkeld MS, Collins TE J. Adequacy of online medical command communication and emergency medical services documentation of informed refusals. Academic Emergency Medicine. 2005 Oct; 12(10): 970-7.

32. Tempereau CE, Grossman AR, Brones MF. Psychological regression and marital status: determinants in psychiatric management of burn victims. Journal of Burn Care \& Rehabilitation. 1987 Jul-Aug; 8(4): 286-91.

33. Vaillant G.E, Bond M, Vaillant C.O. An Empirically Validated Hierarchy of Defense Mechanisms. Arch Gen Psychiatry. 1986 Aug; 43(8): 786-94.

34. Weiten W. Psychology: Themes and Variations. Sixth ed. Southbank (Australia): Thomson/Wadsworth; 2004

35. Westaby S, Channon K, Banning A. To stent or not to stent?: A sterile debate.[comment]. BMJ. 2007 Jul 21;335(7611):111.

Received: 05/04/2010. Accepted in revised form: 19/08/2010.

\section{Corresponding author:}

Andrei M Beliaev, Surgical Registrar, Ph.D, General Surgery Department, Middlemore Hospital, Private Bag 93311, Otahuhu, Auckland 1640, New Zealand; e-mail: Andrei.Belyaev@middlemore.co.nz 